\title{
'PATCHWORKER': CONSTRUÇÃO BIOGRÁFICA E ATITUDES PROFISSIONAIS - ESTUDO DAS MOTIVAÇÕES DOS ESTUDANTES ALEMÃES DURANTE OS ÚLTIMOS 30 ANOS
}

\author{
PETER ALHEIT \\ Universidade de Göttingen, Alemanha \\ Tradução do inglês por Camila Schmitz Röwer
}

RESUMO O texto estuda as dimensões sociais direta e indiretamente relacionadas ao desenvolvimento de um habitus profissional vinculado à educação de adultos (formação universitária). A coleta de dados realizada nos últimos 30 anos reúne narrativas e escritas autobiográficas, entrevistas realizadas com ingressantes em cursos de formação profissional universitária. Objetiva verificar se padrões biográficos predestinam os envolvidos a suas escolhas de formação profissional, ou, se, ao contrário, a educação superior atrai grupos específicos. Esta pesquisa social vincula-se ao vasto campo da sociologia das ocupações, e foi desenvolvida em uma universidade do norte da República Federal da Alemanha. As conclusões deste trabalho indicam que os sujeitos envolvidos são vítimas prováveis de uma fraude estrutural causada pela modernização das sociedades. No processo de mobilidade sociocultural ascendente, o habitual mundo da vida perde sua significância 'natural', como horizonte de formação de conhecimento guiando interações do dia a dia. Prescrições profundamente enraizadas para lidar com a realidade - mentalidades tradicionais e formas de habitus - tornam-se instáveis e ameaçadas de dissolução. Regras convencionais do ambiente social original perdem sua importância e são substituídas por novos meios sociais. Modelos biográficos são desvalorizados e não têm sucessores funcionais. Através deste processo é desenvolvido pelos indivíduos um certo 'desapego' de ações contingenciais, em seus respectivos ambientes 'naturais', no limitado `setor aberto' do espaço social modernizado.

Palavras-chave: Habitus profissional. Educação de adultos. Sociologia das ocupações. 


\section{THE LAST 30 YEARS}

The text study the directly and indirectly social dimensions related to the development of a professional habitus linked to adult education (university education). The research, which gathers data (narratives and (auto)biographical writings) collected in the last 30 years, intent to verify if biographical patterns predestine individuals involved with their professional training choices or, if instead, adult education attracts specific target groups. This social research is linked to the vast field of the sociology of occupations and was developed in a university at north of the Federal Republic of Germany through the recollection of data and information with (auto)biographical interviews conducted with new students joining the university course. The conclusions obtained with this work indicate that the subjects involved are probable victims of a structural fraud caused by the modernization of the societies. In the process of upward socio-cultural mobility, customary lifeworld loses its 'natural' significance as horizon-forming knowledge guiding everyday interactions. Deeply anchored prescriptions for coping with reality - traditional mentalities and forms of habitus - become unstable and threaten to dissolve. Conventional rules of the original social environment lose their importance and are replaced by new social milieus. Biographical models are devaluated and have no functional successors. Through this process, a certain 'detachment' of contingent actions is developed by individuals from their 'natural' environments, in the narrow 'opening sector' of the modernized social space.

Keywords: Professional habitus. Adult education. Sociology of occupations.

'PATCHWORKER': CONSTRUCCIÓN BIOGRÁFICA Y ACTITUDES PROFESIONALES- ESTÚDIO DE LAS MOTIVACIONES DE LOS ESTUDIANTES ALEMANES DURANTE LOS ÚLTIMOS TREINTA AÑOS

El texto estudia las dimensiones sociales directa e indirectamente relacionadas con el desarrollo de un habitus profesional vinculado a la educación de adultos (formación universitaria). La recolección de datos realizada en los últimos 30 años incluye las narrativas y escritos autobiográficos, entrevistas realizadas a estudiantes que 
ingresan a cursos de formación profesional universitaria. Se tiene como objetivo verificar si patrones biográficos predestinan a los involucrados en sus opciones de formación profesional, o si, por el contrario, la educación superior atrae a grupos específicos. Esta investigación social se vincula con el vasto campo de la sociología de las ocupaciones, y se desarrolló en una universidad del norte de Alemania. Las conclusiones de este trabajo indican que los sujetos implicados son probables víctimas de un fraude estructural causado por la modernización de las sociedades. En el proceso de movilidad sociocultural ascendente, el habitual mundo de la vida pierde su significado "natural", como horizonte de formación de conocimiento guiando interacciones cotidianas. Prescripciones profundamente arraigadas para hacer frente a la realidad - mentalidades tradicionales y formas de habitus - se tornan inestables y amenazadas de disolución. Reglas convencionales del entorno social de origen pierden su importancia y son reemplazadas por los nuevos medios sociales. Modelos biográficos son desvalorizados y no tienen sucesores funcionales. A través de este proceso, un cierto "desapego" a las acciones contingentes es desarrollado por individuos, en sus respectivos entornos naturales, en el restringido 'sector de la apertura' del espacio social modernizado.

Palabras clave: Habitus profesional. Educación de adultos. Sociología de las ocupaciones.

\section{Introdução}

Um dos componentes 'secretos' do nosso conhecimento comum, e que tem sido objeto de intensa pesquisa sociológica, pelo menos nos últimos anos, é que certas atividades formam um habitus específico (KORING, 1990, p. 8 s.). Conhecemos este fenômeno das profissões clássicas - médicos, teólogos e advogados. Também o conhecemos das análises biográficas de ocupações 'modernas', altamente interessantes, como técnicos e jornalistas (HERMANNS, TKOCZ; WINKLER, 1984; MÖDING; VON PLATO, 1989). Por habitus entende-se - usando as palavras de Bourdieu (1987) - uma série de rotinas, padrões de interpretação, assim como scripts da linguagem corporal, que foram 'gravadas', por assim dizer, através da socialização profissional e de muitos anos de prática, tor- nando-se um tipo histórico - e mesmo tácito - de conhecimento. Quanto mais tradicional a profissão, mais visível e aparente é este habitus profissional. O patriarcal e sonoro médico chefe com seu jovial 'e como estamos todos hoje?' o clérigo, que é pastoral no seu comportamento até em conversas privadas, ou o 'ganancioso' e 'perverso' economista - todas estas são obviamente caricaturas, porém, verdadeiras, num certo sentido.

As assim chamadas 'novas ocupações' (HERRMANN, 1990), especialmente na área da educação e de serviços de assistência social, são caracterizadas menos facilmente. Elas geralmente não dispõem de códigos profissionais de comportamentos estabelecidos, nem de um preceito de conhecimento tradicional e 
comprovado (OEVERMANN, 1981; KORING, 1987). Contudo, os mais importantes estudos empíricos recentes sobre profissões foram produzidos precisamente neste campo, e uma das áreas mais produtivas para tal pesquisa parece ser a de educação de adultos. Não é de surpreender que a pesquisa biográfica goze de uma posição de certa importância nesta conexão (GIESECKE, 1989; KADE, 1989). Não seria completamente absurdo assumir que a procura de um habitus profissional, por aqueles engajados na educação continuada de adultos, poderia ser a expressão empírica de uma profunda crise de identidade profissional (ALHEIT, 1993a; 2010; 2014).

Este não seria o lugar para debater nenhum estudo de grande escala sobre profissões. Minha análise diz respeito a uma questão periférica, as dimensões sociais que estão relacionadas somente, e de forma indireta, ao desenvolvimento de um habitus profissional designadamente: como as pessoas decidem em primeiro lugar assumir estudos de educação de adultos? Os padrões biográficos que predestinam indivíduos a tal curso de estudos podem serem identificados? Ou, por outro lado, a educação de adultos atrai grupos-alvo específicos?

O material apresentado não decorre de um estudo de grande escala, na sociologia das ocupações, mas é um surpreendente subproduto de aulas teóricas. Aproximadamente, durante os últimos 30 anos, introduções a métodos qualitativos de pesquisa social têm sido realizadas regularmente em cursos de graduação universitária - de educação de adultos em uma universidade no Norte da Alemanha. Alguns dos grupos ${ }^{1}$ de projetos dos estudantes estavam motivados, neste contexto, a conduzir entrevistas biográficas com novos estudantes que estavam ingressando em cursos $^{2}$ univer-

1 O conceito didático por trás destes seminários e palestras dadas por mim e por minhas assistentes contemplam projetos de pesquisa claramente definidos, realizados por grupos de trabalho sobre questões de pesquisa, que foram selecionadas por eles mesmos.

2 Um total de 58 extensas entrevistas narrativas foram sitários. Os resultados obtidos são notáveis, em vários aspectos. Em particular, a mudança evidente no perfil do estudante leva a conclusões cautelosas, que serão apresentadas a seguir. Primeiramente, eu irei apresentar alguns dados qualitativos que são reconhecidamente seletivos, e claro, particularmente marcantes. Em segundo lugar, eu darei sequência a uma tentativa de colocar os resultados obtidos num contexto teórico mais amplo.

\section{Modificações de características no perfil de estudantes de educação contínua: de 'clientelismo' para 'pós-modernismo'}

Uma breve síntese do sistema alemão de educação e de formação contínua deveria ajudar os educadores de adultos na América do Sul, que não estão familiarizados com esse sistema para reconhecer as questões envolvidas. De certa forma, 'educação de adultos' é a variante moderna da educação popular que Adorno descreveu, em meados da década de 1950, como exercendo uma função de 'preenchimento de lacuna' e 'periférica', dentro do sistema de educação alemão no seu conjunto (ADORNO [1956], 1975, p. 15). Embora existam alguns termos ou conceitos que tiveram uma carreira mais de alto nível, desde a introdução da educação contínua [Weiterbildung], rotula-

realizadas, em quatro ciclos de entrevistas, entre 1984 e 2007. Cada grupo de projeto, em separado, usou o procedimento teórico de amostragem, desenvolvido por Barney Glaser e Anselm Strauss (1967), para determinar a amostra a ser entrevistada (STRAUSS, 1991; ALHEIT, 1994a). Para chegar ao material apresentado aqui, eu também desenvolvi uma amostragem teóri$\mathrm{ca}$, a fim de obter casos de estudo contrastantes, que claramente ilustram os pontos levantados. Os trechos da entrevista aqui interpretados são 'subprodutos', por assim dizer, do que foi inicialmente um processo 'aberto', mas subsequentemente um 'processo de codificação seletivo' (STRAUSS, 1991). Isso porque, minha própria intensa experiência como professor, durante o período em questão, me proporcionou um conhecimento contextual muito superior sobre o assunto de interesse. 
da na década de 1970 Plano Estrutural para o Sistema Educacional [Strukturplan für das Bildungswesen], o aspecto 'preenchedor de lacu$n a$ ' foi fixado. A assim chamada 'virada realista', a crescente institucionalização do novo 'setor educacional quaternário' e, sobretudo, o crescimento de sua importância para o mercado de trabalho,nada fez para mudar isto (ALHEIT 1993b); da mesma forma, não contribuiu para uma mudança, o maior caráter 'científico' ou acadêmico dos cursos, que tem sido associado, desde o início da década de 1970, com o aumento do número de departamentos de educação de adultos nas universidades alemãs. Em todo caso, estes não resultaram, em nenhum sentido, em tornar a profissão mais estabelecida e importante, mas a conduziram a uma mistura fluída de qualificações básicas que incluem aspectos de especializações, sociais, organizacionais, de entretenimento e ocasionalmente carismáticas, condensando um habitus profissional independente (AXMACHER 1990, p. 30). Então, como alguém acaba querendo adquirir este habitus, iniciando um curso de estudo deste tipo, um habitus de tal fluidez oscilante que crises secretas de autoestima são criadas pela mera questão que pessoas leigas possam colocar, designadamente 'o que realmente é?' e 'o que você aprende?'

\section{Tipo de caso 1: Brigitte $^{3}$}

Brigitte nasceu no início da década de 1940, no sul da Alemanha, vem de uma família protestante de classe média e se considera um membro da 'geração 68'. Ela começou uma graduação em sociologia, numa grande cidade no oeste alemão, durante o tempo dos movimentos estudantis, mas descontinuou os estudos, quando se casou cedo e teve uma filha. No entanto, ela sempre esteve socialmente envolvida, enquanto suas duas crianças eram ainda bebês

3 Todos os nomes usados para descrever tipos de casos são pseudônimos. (ela teve um filho um ano depois do nascimento de sua filha), e seu esposo, um liberal e bemsucedido homem de negócios da indústria, no setor de alta tecnologia, a apoia neste aspecto. Primeiramente, ela era ativa numa creche auto-organizada, e mais tarde num projeto para ajudar os sem-teto. Desde meados da década de 1970, ela está envolvida em organizar apoio aos trabalhadores migrantes - especialmente da Itália - e tem adquirido experiências na área da educação de adultos com estes grupos.

Ela avança nesta experiência e se torna uma especialista em trabalho cultural, dentro da comunidade local. Durante os próximos cinco anos, ela organiza, juntamente com várias outras instituições de educação adulta, um ciclo de projetos interessantes, no campo da educação e cultura, também atuando na qualidade de professora de meio período. Em sua biografia, ela descreve isso como sendo um período muito interessante e entusiasmante, no qual ela aprendeu muito mais que durante o movimento estudantil.

A família muda-se para o norte da Alemanha, no início da década de 1980, devido ao novo trabalho de seu esposo. Num primeiro momento, ela está frustrada, mas decide, relativamente rápido, a voltar para a universidade e fazer um curso em educação de adultos, no novo departamento instalado na universidade local. Em uma 'passagem central'4 de sua narrativa biográfica, ela diz:

Bem, Jenny e Erik eram agora, como se costuma dizer, basicamente maiores - Quero dizer que eram grandes, eles apenas estavam fora do caminho, fazendo suas próprias coisas.

4 'Passagem central', como já sugerido na nota de rodapé 2, são os resultados de processos avançados de interpretação (codificação). A notação usada para transcrever os itens de texto é de uma simplicidade que auxilia a leitura - transcrição literária próxima ao texto falado e legivel, através do uso de pontuação convencional: notação de proposições singulares; traços ('-'), para marcar cesura prosódica; sublinhando ('você sabe?'), para demonstrar tensão empática; uso de colchetes ('[...]') para fazer com que o nome de lugares sejam anônimos ou para explicar novos nomes. 
Dieter [o esposo] tinha seu trabalho e quase nunca estava em casa e eu estava somente sentada ali, mal conhecia alguém.

E a coisa principal é que: - eu sentia falta do meu trabalho, terrivelmente, este negócio de fazer alguma coisa para outros.

Às vezes eu deitava e chorava, sentindo-me bem supérflua, num limbo.

Bem - e aí eu tinha acabado de ouvir falar deste novo curso de graduação...

E, para ser honesta, em primeiro lugar, eu não sabia o que esta palavra significava.

De qualquer forma, eu simplesmente segui o fluxo, entrei para este seminário.

E, achei ele ok.

De qualquer modo, estava claro que isto era o que eu queria fazer.

Isso sempre me incomodou: - que eu não terminei aquela coisa acadêmica devidamente.

Então eu queria fazê-la... 'foi um grande desafio inicialmente...

O que com Dieter dissesse 'Uni? Que bem que isso fará a você? e assim por diante.

E as crianças perguntando: - 'Quem fará o serviço de casa?'...

Isso me irritou!

Eu apenas me decidi, muito simplesmente.

E, de certa forma, era a continuação do trabalho que já estava fazendo.

Sintomaticamente, Brigitte começa esta passagem a uma virada crucial em sua biografia ocupacional, com uma referência a sua família. Ela 'justifica' sua decisão posterior de começar um curso de estudos na universidade: as crianças estão maiores, seu marido está absorvido em seu trabalho. Tal mulher, ativa e autoconfiante, obviamente sente a necessidade de pensar se sua futura formação profissional prejudicará a sua vida familiar. Até mesmo o fato de que todos os outros membros da família parecem já estar seguindo os seus próprios e respectivos caminhos, proporciona a ela so- mente uma estrutura de legitimação. Mulheres, em contraste com homens, tendem a amarrar a decisão em favor de uma ocupação, uma decisão que é tão séria para elas quanto para os homens, com ambivalências, essencialmente porque ter uma ocupação não reduz a questão das relações familiares internas a uma de importância secundária (DAUSIEN, 1996).

Por outro lado, a opção de seguir uma ocupação, no caso da Brigitte, não é alguma falsa estratégia de evasão. Ela não está completamente realizada pela situação familiar. Mais dramaticamente ainda, ela estava 'sentindo falta de seu trabalho, terrivelmente'. É sintomático que a protagonista classifique suas várias atividades de meio período como trabalho. As conotações do termo parecem integrar ambos os aspectos para ela - competência ocupacional ou especialista ('meu trabalho'), e também a necessidade social, e talvez política, que se encontra atrás de seu envolvimento ('este negócio de fazer alguma coisa para outros'). A experiência de ser marginalizada ('... sentei $e$ chorei ... supérflua ... num limbo') são claras indicações disto.

O 'novo curso de graduação' é como um tipo de âncora. De modo algum, ele parece ter sido uma saída dada por garantida. Ela nem tem certeza, inicialmente, do que o curso envolve, na realidade, em termos de conteúdo ('para ser honesta, em primeiro lugar, eu não sabia o que esta palavra significava'). A reação da Brigitte é claramente de caráter pragmático. Ela não toma sua decisão baseada em algum entusiasmo ingênuo, embora ela saiba que o número de alternativas é limitado. Ela 'simplesmente seguiu o fluxo' e adquiriu sua própria impressão. Seu julgamento positivo é a condição prévia da decisão final em favor dos estudos ('... achei ele ok').

o fato de que sua decisão é baseada no pragmático, ao invés de considerações emocionais, se confirma mais uma vez pelo uso 
do adverbial 'de qualquer modo' ('De qualquer modo estava claro'). Ambivalências biográficas e situacionais não estão completamente removidas. Em vez disso, recorreu a ambivalências adormecidas ('aquela coisa acadêmica'). A própria formulação distanciada que ela usa neste contexto - 'aquela coisa acadêmica' - mostra que o problema para Brigitte não é tanto o curso em si, mas o fato de que existe uma pendência em sua biografia ('não terminei aquela coisa acadêmica devidamente'). E ela não tem desejo algum em continuar a graduação de sociologia que ela estava fazendo, naquela época, mas, sim, prosseguir no trabalho que ela fazia onde costumava viver. Como filha de um lar protestante de classe média, não é tanto na carreira, mas no assunto em si que ela está interessada. Porém, seu interesse não está isento de problemas. 0 preconceito de gênero entra em vigor. Esposo e filhos exigem dela a presença da dona de casa. Pela segunda vez, Brigitte usa a expressão conotativa 'me incomodou', em conexão com a decisão autônoma que ela tomou, mas agora não poderá haver mais negociações de função - a questão é a sua própria consistência e continuidade biográfica ('uma continuação do trabalho que já estava fazendo').

A decisão de dedicar-se aos estudos de educação adulta tem algo a ver com uma combinação específica - isto é particularmente evidente, através das ambivalências e interrupções da biografia feminina. O curso universitário é uma continuação de algo já existente em sua biografia. Brigitte exemplifica, num certo sentido, um determinado tipo de característica de estudantes de educação de adultos, durante a década de 1980 , socialmente e politicamente comprometidos - pessoas com experiências especificas, sociais ou políticas, ocupacionais ou semiocupacionais, que esperam ver continuadas e consolidadas, através de estudos mais aprofundados. Inicialmente, o curso não é visto como uma situação independente da sociali- zação ocupacional, mas sim como uma fase no processo de formação do habitus, que há muito tempo já havia começado.

Werner, um estudante da mesma geração, com muitos anos de experiência em formação profissional contínua, assim se expressa:

Claro, eu quero tirar algum proveito do curso.

Eu também posso me imaginar entrando em contato com algumas ideias novas,...

Quero dizer, novas descobertas nesta área, basicamente estímulo - veremos o que acontecerá...

Mas, a razão principal pela qual eu estou iniciando isto é meio que: - embarcar em uma carreira profissional, não necessariamente para fazer sucesso. Embora, ... - por que não?

A motivação inicial, no caso de Werner, é mais pragmática, quase instrumental, em sua natureza. 0 propósito de estudar está em aprimorar seu nivel atual de profissionalismo (' $f a$ zer sucesso ... por que não?').

Klaus descreve isto de uma maneira um pouco diferente:

Bem, eu sempre vi meu trabalho pedagógico em termos políticos.

Isso foi o que me fez voltar à universidade.

De qualquer maneira, ouvi dizer, que tais e tais pessoas estão aqui na universidade,...

então aqui estou!

Klaus é politicamente motivado, mas ele também vê seus estudos futuros como uma continuação de sua prática anterior (profissional/política). Estudar educação de adultos é uma fase mais ou menos importante, no que é essencialmente um processo de qualificação linearmente concebido.

Surpreendentemente, a gama de assuntos específicos oferecidos dentro do departamento, durante a década de 1980, parecem ter levado estas opções ocultas em consideração. Além de uma ilimitada e inespecífica seleção 
básica de cursos, em áreas como didática, organização e aconselhamento em educação de adultos, existe também uma riqueza de aulas teóricas e seminários 'profissionais', mas acima de tudo, orientação política. Na verdade, parece quase como se as diversas 'necessidades de harmonização' correspondessem a um tipo de cultura de dependência ou até mesmo 'clientelismo', por parte do próprio corpo docente - alguns deles satisfazem continuamente a demanda por temas relacionados à união sindical em educação, outros, regularmente, abordam grandes problemas na história política de esquerda, enquanto outros novamente concentram o curso que eles oferecem para clientes de formação profissional ou formação profissional contínua, dentro de empresas.

No entanto, no decorrer da década de 1990, a situação parece ter sofrido mudanças dramáticas. 'Clientelismo' - se o termo pode mesmo ser utilizado neste contexto - é encontrado somente no campo dos estudos feministas. Os perfis biográficos e as 'necessidades de harmonização' de estudantes normais (regulares), no presente momento, foram claramente modificados.

\section{Tipo de caso 2: Mike}

Mike nasceu no fim da década de 1960 e vem de uma pequena cidade do Norte da Alemanha. Seu meio de origem é mais 'um pequeno proletário burguês'. Seu pai é um instalador de fogões. Entretanto, ele tem ambições maiores para seus filhos (Mike é o seu filho mais ve(ho). Eles deveriam aprender algo e conquistar mais na vida do que ele conseguiu. Para alcançar este objetivo, ele liderou um regime autoritário na família, monitorando regularmente o desempenho escolar. Por exemplo, Mike, de acordo com suas próprias palavras, "sempre tive o sentimento de não estar vivendo à altura do que o pai esperava".

Suas notas na escola são medíocres. Depois de deixar o ensino médio, ele aprende carpintaria, um oficio que não lhe permitirá ganhar muito dinheiro. Depois de passar nos exames, ele faz trabalhos temporários, antes de ir para uma escola técnica. Ele gosta de estudar, mas não tem perspectiva profissional. Ele deixa a escola técnica com um certificado padrão e segue para uma graduação em engenharia, que ele abandona depois do primeiro período, porque ele 'odeia todo aquele estudo intenso', como ele mesmo coloca.

Ele trabalha por mais de um ano como um barman num bar 'badalado', mas acaba decidindo voltar para o politécnico e estudar sociologia. Quando ele completa sua graduação, não há mais trabalhos nesta área, e ele é forçado mais uma vez a aceitar qualquer trabalho que encontre. Diversos bares, eventuais pesquisas de opinião para institutos de pesquisa, e trabalhos como guia no Oriente Médio, são algumas das várias 'paradas' que ele fez.

Aos 30 anos de idade, ele decide estudar educação de adultos. Numa parte importante em sua entrevista, ele diz:

Que louco!

Sempre este sentimento de que 'isto não é o que eu realmente estou buscando. Sempre começando do zero.

A mesma coisa provavelmente acontecerá de novo com este curso.

Estou fazendo ele, até mesmo gostando dele, mas nada virá dele.

Quero dizer, poderia ser diferente, claro,...

Digo, educação de adultos soa muito bem $e$ tudo mais.

Mas então - como alguns dos meus amigos disseram, isso não rende tanto em relação ao aprendizado e tudo mais que diz respeito.

o que eu quero dizer: - você pode trabalhar por fora também.

É isso que eu estou procurando. E é o tipo de coisa que preciso.

Eu apenas me pergunto se isso me levará a algum lugar? 
Mike começa sua introdução ao tema 'educação de adultos', na sua narrativa biográfica, com uma sucinta análise de sua situação - 'Que louco... sempre começando do zero'. Sua repetição de 'sempre', indica um tipo de 'ritual de enquadramento'. Mike está abordando um motivo central de sua biografia, uma 'peça-chave', por assim dizer: 'isto não é o que eu realmente estou buscando'. E ele insere esta estrutura na passagem citada da sua biografia narrativa, de várias formas diferentes. Sua 'má profecia' - 'A mesma coisa provavelmente acontecerá de novo com este curso' - é um exemplo, assim como é a fatalista sequência de decisões, prazer e fracasso. Contudo, ainda assim, a alternativa possível é mencionada ('poderia ser diferente, claro'), e vinculada conotativamente aos seus estudos de educação adulta.

o que é impressionante aqui é que o narrador, inicialmente, não explica suas associações positivas, em termos racionais, mas, em vez disso, esteticamente ('soa muito bem'). Somente numa segunda abordagem, ele fornece argumentos pragmáticos - seus 'amigos' acreditam que o que ele está fazendo é uma coisa boa; as exigências impostas sobre ele não são excessivas, e ele pode 'trabalhar por fora também', um aspecto que pode ser vital para sua sobrevivência econômica. Mike resume dizendo: 'É isso que eu estou procurando e é o tipo de coisa que preciso', ou, parafraseando, um pouco ironicamente, um envolvimento que soa bem, não me causa estresse, onde posso trabalhar à parte. A pergunta preocupante -

'Eu apenas me pergunto se me levará a algum lugar?' - no fim da sequência, nos leva de volta ao princípio de realidade.

As disposições de Mike não são representativas, em nenhum sentido estatístico, claro, mas são típicas no sentido de uma 'lei', que opera para um caso individual, como Kurt Lewin (1969 [1931]) tem tão convincentemente argumentado. A dinâmica da biografia educa- cional de Mike nos confronta com um elemento-chave no campo que estamos observando. Isto é demonstrado claramente por algumas passagens de outras entrevistas.

Valina resume suas qualificações de experiências anteriores, do seguinte modo:

Todas as coisas que já fiz, ou tentei,... duas graduações, adquirindo minha primeira experiência prática de novo e de novo.

Interrompida sempre de novo por causa das crianças,...

Novos temas - ambientes - mulheres - corpo dança, sistema de criação de emprego [emprego 'fictício' ao invés de benefício da segurança social],...fim!

Sou cética sobre esta coisa de educação adulta.

Mas o que mais posso fazer?

Listagens como estas evocam imagens de biografia como um 'patchwork' - pelo menos à primeira vista: muitas peças separadas, quase colagens, mas apenas poucas linhas visiveis. 0 mesmo se aplica a Doris:

Ouça!

Eu tenho procurado pela coisa certa para mim há anos.

Eu parei de ser uma enfermeira, porque estava - me destruindo.

Cara, já fiz terapias, duas, três, ...

Daí escola, suficientemente dura para mim, e agora este curso universitário.

Você sabe, de certa forma, é como se estivesse procurando alguma coisa.

Em contraste, as experiências biográficas destas pessoas - Brigitte, Werner e Klaus -não podem ser usadas como recursos, pelo menos não na esfera ocupacional. Em vez disso, elas são praticamente passagens independentes num estranho tipo de processo de busca, o ponto final em que o curso de educação de adultos obtém um status extraordinariamente arbitrário. 
Isto talvez explique o fato de que a gama de cursos oferecida pelo departamento sofreu mudanças, durante a década de 1990. O 'clientelismo' é substituído por certa consolidação e expansão da gama básica de cursos baseados em profissões. A arbitrariedade também aumenta, embora exista uma ascensão inflacionária em temas culturais, 'mundo da vida' se torna um conceito programático, em cursos especiais de teatro, vídeo. Até mesmo meditação e temas esotéricos estão inclusos. As 'estrelas', contudo, são as questões baseadas em gênero. Seminários expressamente para homens estão também integrados ao programa.

Não é exagero falar de uma 'pós-modernização' do currículo. Aos 'patchworkers' é oferecido um cenário universitário, na forma de 'colagens' - referências esporádicas para significados específicos, sem qualquer forma genuína de 'metanarrativa' ou entendimento comum, embelezado arbitrariamente sem qualquer consistência de legitimação. Este resultado parece sintomático. Ele também nos leva a alguma interpretação teórica plausível?

\section{‘Patchworkers': o ‘multiplamente enganado'}

Pelo seu valor, a mudança do tipo de caso, de 'Brigitte' para o de 'Mike', representa somente uma disposição alterada em direção ao curso de educação de adultos. De fato, porém, existe uma exacerbação considerável de padrões de construção biográfica. Embora Brigitte seja capaz de sistematicamente empregar seus recursos biográficos com o fim de integrar com sucesso a nova experiência de aprendizado, no seu conjunto de experiências, por meio de tentativas e de tipificações testadas, Mike é obrigado a reagrupar seu arsenal de tipificações, mais uma vez, quando ele começa o curso. 0 biográfico 'patchworking', em que sua graduação de educação de adultos está inserida é in- dicativo de um problema específico.

As ideias seguintes não visam apoiar esta observação com dados empíricos, mas são, sim, uma tentativa de fornecer uma explicação teórica, que é mais que simplesmente 'relacionada ao objeto'. É uma variação de ideias apresentadas por Jeffrey Alexander, quem vê as relações entre ações sociais e seus vários 'ambientes' como sendo a localização crítica para a integração teórica de afirmações micro e macrossociológicas (ALEXANDER, 1993, p. 196s.). A intenção é, portanto, descrever ações biográficas contingentes, ambas teórica e empiricamente, como interações com ambientes específicos e definir estes ambientes como produtos de ações biográficas.

\section{A erosão de ambientes de ações biográficas}

Não há nada revolucionário na ideia de que ações contingentes possuem 'ambientes' (PARSONS, 1966). O que é notável é que as microssociologias clássicas, independente se a abordagem é incluída no paradigma interpretativo, ou o mais recente conceito de escolha racional, não são capazes de fornecer um modelo ator -ambiente útil, pela simples razão que elas desassociam a própria ação de seus ambientes - seja ela de natureza ecológica ou situacionista, ou informada por um foco estritamente racionalista (ALEXANDER, 1993, p. 199s.). Em outras palavras, talvez vivenciemos muito sobre como atores sociais retratam seus ambientes de ações, como eles 'moldam' estes ambientes, a partir de suas próprias perspectivas e com seus próprios conhecimentos, conscientes e subconscientes, disponiveis, que cálculos fazem sobre as consequências de suas ações etc., mas temos pouca percepção destes ambientes como tal.

Jeffrey Alexander adota as três sistêmicas clássicas de ambientes de ação de Parsons 
(1966): 'cultura', 'sociedade' e 'personalidade' (ALEXANDER, 1993, p. 204s.). O conhecimento que adquirimos destes ambientes, não apenas para avaliações racionais de ação, mas também para cálculos intuitivos e tipificações necessárias, é 'construído' de tal forma que trata de novos fenômenos como se fossem fatos sociais que são conhecidos há muito tempo. Se tipificações estabelecidas e cálculos implícitos e explícitos não bastam, então o lugar deles é tomado por 'invenções' que compensam a perda de orientação. Tudo isso é normal e é um componente da ação quotidiana. Somente quando o ambiente de ação social muda tão drasticamente, de modo que não se estabelecem novas e suficientes tipificações, somos possivelmente forçados a lançar até cálculos intuitivos para narrar a história de nossas vidas numa forma completamente nova (ALHEIT, 1996). Este caso, porém, pode somente ser esperado em situações sociais particularmente precárias, mas o grupo-alvo que estamos tratando aqui poderia ser especialmente vulnerável a este desenvolvimento precário. Procedimentos sobre esta suposição teriam o benefício da hipótese implícita de que o ambiente de ações contingentes - cultura, sociedade e personalidade, com seus recursos de tradição, solidariedade e identidade (HABERMAS, 1981, II, p. 211s.) - não são de forma alguma constantes universais, mas, em vez disso, dependem da posição de atores no espaço social (BOURDIEU, 1987). Cultura então aparece especificamente como socialização de formação de horizonte, isto é, como 'mundo da vida', ou o mundo social ao alcance. Sociedade é, sobretudo, a dimensão de integração social, como vivenciada no nível de comunidade, isto é, o meio social a que pertenço. $E$ personalidade é responsável pela ação de 'biografar' minha individualidade, que devo desempenhar sempre que tiver um lugar na sociedade: a contínua sincronização da experiência que eu real- mente tenho com a experiência que eu mesmo acredito ter - a engenharia constante de consistência e continuidade do meu "eu".

Vamos agora imaginar que os recursos de formação de horizonte dos padrões culturais internalizados, como o habitus incorporado que adquirimos, repentinamente perdessem todo o seu valor. Imaginemos também que temos que deixar, voluntaria ou obrigatoriamente, nosso meio social original. Por fim, imagine que tudo isso conduza à "reescrita" de nossa biografia. Isto praticamente seria o ponto crítico onde os 'ambientes' de nossas ações estão mudando tão rapidamente que reações seriam inevitáveis (ALHEIT, 1996).

\section{‘Abertura' e 'fechamento' do espaço social}

Nos últimos 30 anos, nos 'velhos' Estados da Alemanha Ocidental, pelo menos, temos de fato observado um dinamismo incrivel no espaço social. Não que a crise que descrevemos seja de forma alguma normalidade. Mas, indícios de que o espaço social está 'abrindo' não podem ser ignorados (BOURDIEU, 1987; VESTER et al., 1992; ALHEIT, 1992; 1994b). E esta abertura tem algo a ver com uma mudança oculta e dramática em ambientes socialmente específicos de ações.

Isto pode ser ilustrado com alguns exemplos bem conhecidos: desde o início dos anos de 1950 até a década de 1980, a porcentagem de crianças de famílias das classes trabalhadoras que estuda tem mais que quadruplicado. Durante o mesmo período, a proporção de mulheres estudantes aumentou de $13 \%$ para quase 40\% (VESTER et al., 1992, p. 166s.). A reforma educacional tem, por isso, criado movimento na estrutura social. Em paralelo a estas mudanças, o número das assim chamadas 'novas ocupações' também vem crescendo. Estas são ocupações que - usando as palavras de 
Bourdieu - requerem uma alta proporção de 'capital cultural' - ocupações em educação e formação, em ciências, profissões artísticas e culturais, ocupações no campo de assistência social (HERRMANN, 1990).

Esta abertura de espaço social é, portanto, relativamente inconfundivel. Se ilustrarmos isso na matriz de Bourdieu, teremos uma mudança dinâmica da célula inferior direita (volume baixo de capital total, pouco capital cultural) para a área superior centro-esquerda (volume de capital total de tamanho médio, crescimento de capital cultural; ver Fig. 1). Evidentemente, este processo de abertura é, de certa forma, problemático, por várias razões. Alpinistas sociais bem-sucedidos - os 'vencedores da modernização', assim dizendo - recebem trabalhos criados através de reformas educacionais como uma recompensa pelos títulos (acadêmicos) recém-adquiridos. Mas entrar nestas novas posições está associado a duas experiências sociais que confundem (ALHEIT, 1993b):

- Eles frequentemente vivenciam que o capital cultural que eles adquiriram, principalmente o capital social que carregam consigo, isto é, o recurso que normalmente chamamos de 'conexões', não é suficiente para 'preencher' a nova posição (ALHEIT, 1993b).

- A expansão de trabalhos e a extensão de acesso social tem um efeito inflacionário sobre o valor do status da nova posição. A mobilidade social ascendente está desvalorizada post festum.

Esta é a categoria na qual o grupo no tipo de caso 1 pode ser classificado - a geração de 'vencedores' no processo de abertura que, em muitos casos, sofrem da sua própria ascensão social. Os sucessores, os 'perdedores' do processo de abertura, são atingidos mais duramente. Bourdieu fala da 'geração enganada' (1987, p. 241s.). Muitos alcançam o 'título' desejado, mas as posições que o acompanham tornaram-se extremamente escassas. A aquisição e a desvalorização do capital cultural caminham lado a lado. 0 processo de mobilidade ascendente passa a ser um 'círculo' e observamos um fechamento do espaço social. Esta é a categoria à qual atribuímos o tipo de caso 2 (ver Fig. 1):

Figura 1: O 'círculo social' da geração patchwork (de acordo com o espaço social de Bourdieu)

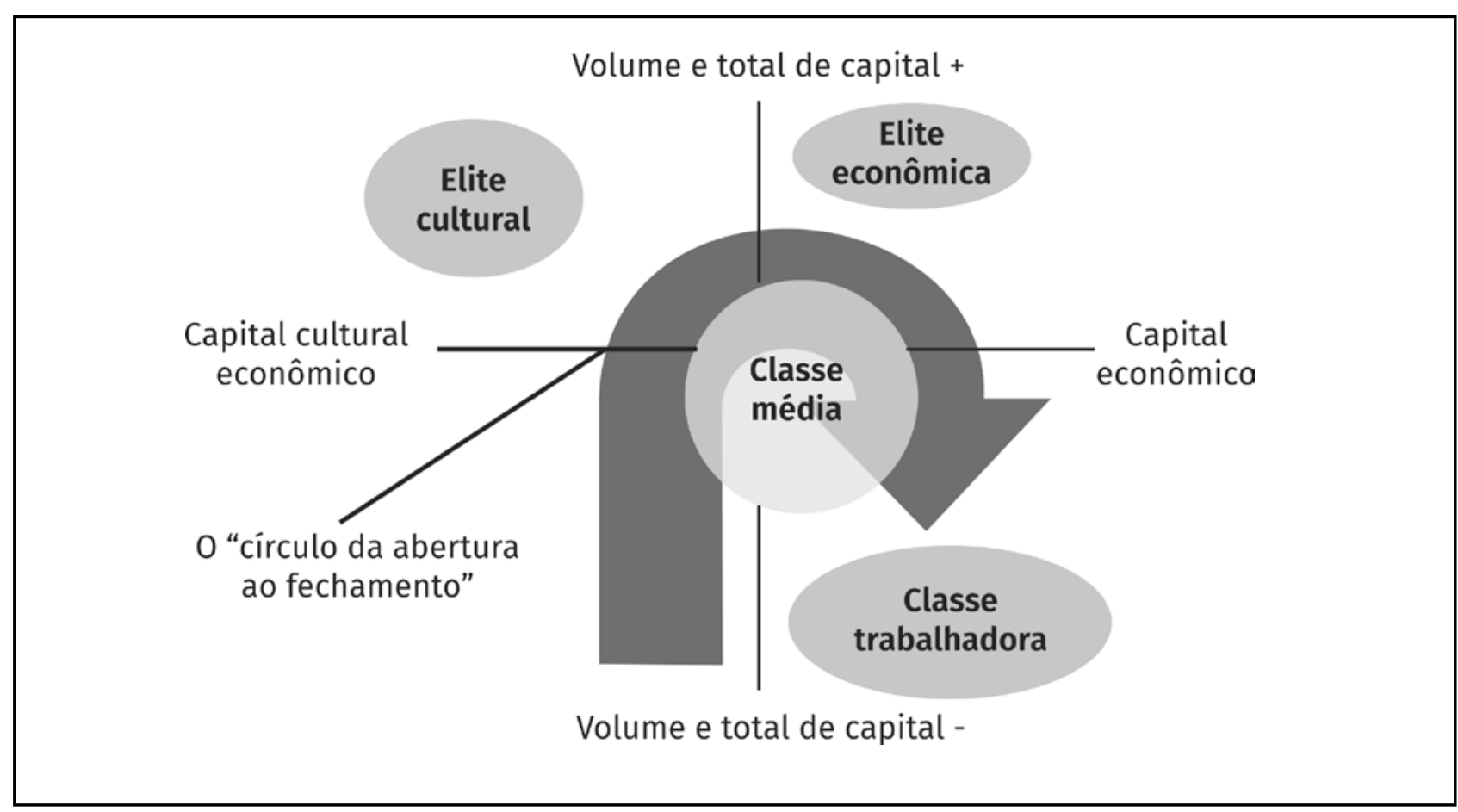




\section{'Patchworkers': vítimas de uma fraude estrutural?}

'Patchworkers' são vítimas prováveis de uma fraude estrutural causada pela modernização das sociedades contemporâneas. No processo de mobilidade sociocultural ascendente, o habitual mundo da vida perde sua significância 'natural', como horizonte de formação de conhecimento guiando as interações do dia a dia. Prescrições profundamente enraizadas por lidar com a realidade - mentalidades tradicionais e formas de habitus - tornam-se instáveis e ameaçadas de dis- solução. Regras convencionais do ambiente social original perdem sua importância e são substituídas por novos meios sociais (ALHEIT; VESTER, 1993). Modelos biográficos são desvalorizados e não têm sucessores funcionais (ALHEIT, 1996). Através deste processo, certo 'desapego' de ações contingentes realmente é desenvolvido pelos indivíduos de seus respectivos ambientes 'naturais', no restrito 'setor de abertura' do espaço social modernizado. Podemos observar três sintomas desta mudança, cada qual relacionado a um dos ambientes de ações descritos acima (ver Fig. 2):

Figura 2: Sintomas de crises no conhecimento comum

\begin{tabular}{|c|c|c|c|c|}
\hline $\begin{array}{c}\text { Niveis gerais } \\
\text { de orientação } \\
\begin{array}{c}\text { Ações intra- } \\
\text { ambientais }\end{array}\end{array}$ & cultura & sociedade & personalidade & recursos \\
\hline $\begin{array}{c}\text { mundo } \\
\text { da vida }\end{array}$ & $\begin{array}{l}\text { riscos de } \\
\text { destradicio- } \\
\text { nalização }\end{array}$ & $\begin{array}{l}\text { colonização" } \\
\text { de recursos do } \\
\text { mundo da vida } \\
\text { tradicional }\end{array}$ & $\begin{array}{l}\text { erosão do } \\
\text { conhecimento } \\
\text { tácito }\end{array}$ & tradição \\
\hline meio social & $\begin{array}{l}\text { perda de } \\
\text { orientação } \\
\text { coletiva }\end{array}$ & $\begin{array}{c}\text { diferenciação } \\
\text { social }\end{array}$ & alienação & solidariedade \\
\hline biografia & $\begin{array}{l}\text { falta de } \\
\text { imagens }\end{array}$ & $\begin{array}{c}\text { perda de } \\
\text { motivação }\end{array}$ & $\begin{array}{c}\text { "artificialização" } \\
\text { da biografia }\end{array}$ & identidade \\
\hline
\end{tabular}

Adaptado de: ALHEIT, 1994b, p. 187 (inspirado em HABERMAS, 1981, II, p. 215).

(1) Destradicionalização latente dos mundos da vida. Certezas do cenário que eram dadas como garantidas, anteriormente, estão se tornando precárias. 0 habitus tradicional de origem perde significância, deixando para trás uma ampla discrepância de orientação. Este sintoma tem sido soberbamente pesquisado em relação aos percursos educativos de me- 
ninas da classe trabalhadora (SCHLÜTER, 1993).

(2) Diferenciação social do meio. Seria um engano acreditar que todos os meios tradicionais são igualmente afetados por tais processos de dissolução. Instabilidades são certamente evidentes nesse 'corredor aberto' do espaço social. Este é o local para uma nítida separação e diferenciação dos meios proletário clássico e pequeno burguês - o cenário do meio para alpinistas sociais (VESTER et al., 2001). Novos meios sociais entram em vigor, cuja consistência pode ser prevista somente com dificuldade. Um dos exemplos mais espetaculares das últimas duas décadas, o chamado 'meio alternativo de esquerda', tem diminuído dramaticamente, após a sua curta carreira nos anos de 1980, e depois está tendendo para 2\% da população (BECKER; BECKER; RUHLAND, 1992, p. 80).

(3) Artificialização da biografia. No processo de desapego forçado dos tradicionais padrões de expectativa, a matriz das biografias modernas também está se tornando mais frágil. Em particular, nas esferas do espaço social, "histórias de vida' não são mais aceitas pelos atores sociais como tentativas para explicar e comunicar sobre eles mesmos e facilmente com outros idealizados, mas, em certas circunstâncias, podem ser 'encenadas', com maior ou menor esforço, ou diversão (SCHEUERMANN, 1994; ALHEIT, 1994b). Algo poderia desenvolver aqui numa forma de comportamento social que expoentes da teoria de sistemas descrevem em termos altamente abstratos, como a necessidade de 'autopoiesis' de sistemas pessoais (NASSEHI; WEBER, 1990).

Para resumir estas observações, podemos afirmar que há claramente uma mudança dinâmica nas disposições e ambientes de ação, numa certa esfera do espaço social. Também está se tornando evidente que sistemas de referência inter-relacionados são extremamente vulneráveis. A crise das prescrições do mundo da vida - um fenômeno do fim do século $X X$, pelo menos na Europa - não produz automaticamente 'novos mundos da vida'.

Para retornar ao nosso exemplo de educação de adulto: 'patchworkers' são obviamente vítimas da abertura e fechamento do espaço social. Patchworking é uma estratégia biográfica para interligar a promessa contínua de ascensão social com a experiência da real exclusão. A escolha por rotas em ascensão não é de forma alguma coincidência - as novas ocupações no campo de 'serviços humanos' são as escolhas primárias, mas os mercados de trabalho relevantes estão praticamente fechados. Entretanto, porque estas rotas de qualificação são justamente aquelas escolhidas pelos potencialmente marginalizados, estes últimos se tornam vítimas de uma 'dupla' exclusão e desvalorização. Aqueles afetados são multiplamente enganados:

- No processo de patchworking forçado, atuais estudantes de educação adulta selecionam 'estudar mundos' com estruturas análogas - qualificação de patchwork sem nenhuma consistência.

- Ambições difusas convergem com meios difusos de opções disponíveis. Qualquer tipo de formação de habitus profissional é bloqueado desde o princípio.

o problema periférico mencionado no começo, isto é, se podemos identificar 'padrões biográficos' que levem à escolha do curso de graduação de educação de adultos, não pode ser respondido com nenhuma finalidade. Uma solução bastante cética e parcial apresenta-se, no entanto. Há obviamente um tipo de complementariedade estrutural entre estruturas características de expectativas e recursos. Para ser mais direto - educação de adultos como uma disciplina acadêmica (pelo menos na Alemanha) seguiu uma 'carreira de patchwork', desde sua breve ascensão social, durante a década de 1970. Em congruência com 
a experiência biográfica de uma proporção substancial de sua posterior clientèle, ela foi submetida a um tipo de 'pós-modernização' de seu próprio perfil. Quaisquer previsões de futuras perspectivas seriam muito arriscadas em relação ao cenário destes resultados, que são

\section{Referências}

ADORNO, Theodor W. Aufklärung ohne Phrasen. In: BECKER, Hellmut. (Ed.). Weiterbildung. Aufklärung Praxis - Theorie 1956-1974. Stuttgart: Klett, 1975. p. 15-18.

ALEXANDER, Jeffrey C. Soziale Differenzierung und kultureller Wandel. Frankfurt am Main; New York: Campus, 1993.

ALHEIT, Peter. Kultur und Gesellschaft. Plädoyers für eine kulturelle Neomoderne (Forschungsreihe des Forschungsschwerpunkts Arbeit und Bildung, Bd. 18). Bremen: Universität Bremen, 1992.

ALHEIT, Peter. Transitorische Bildungsprozesse. Das biographische Paradigma in der Weiterbildung. In: MADER, Wilhelm. (Ed.). Weiterbildung und Gesellschaft. Grundlagen wissenschaftlicher und beruflicher Praxis in der Bundesrepublik Deutschland (Forschungsreihe des Forschungsschwerpunkts Arbeit und Bildung, Bd. 17). Bremen: Universität Bremen, 1993a. p. 343-417.

ALHEIT, Peter. Die Ambivalenz von Bildung in modernen Gesellschaften: Strukturprinzip kumulativer Ungleichheit oder Potential biographischer Handlungsautonimie? Pädagogische Rundschau, 47, p. 53-67, 1993b.

ALHEIT, Peter. Taking the Knocks. Youth Unemployment and Biography - A Qualitative Analysis. London, Cassell, 1994a.

ALHEIT, Peter. Zivile Kultur. Verlust und Wiederaneignung der Moderne. Frankfurt am Main; New York, Campus, 1994b.

ALHEIT, Peter. Changing basic rules of biographical construction: Modern biographies at the end of the 20th century. In: WEYMANN, Ansgar; HEINZ, Heinz. um tanto limitadas em sua aplicação. Levando em conta as informações apresentadas aqui, um habitus ocupacional estável e resistente não pode ser esperado, por enquanto, no campo acadêmico de educação de adultos na Alemanha.

(Eds.). Biography and society. Interrelationships between social structure, institutions and the life course. Weinheim: Deutscher Studienverlag, 1996. p. 111-128.

ALHEIT, Peter. Lifelong learning and social sapital. In: EVANS, Rob. (Ed.). Local Development, community and adult learning - Learning landscapes between mainstream and the margins. Duisburg: Nisaba Verlag, 2010. p. 27-48.

ALHEIT, Peter. Exklusionsmechanismen des universitären Habitus: Exemplarische Studien zur neuen deutschen Universität. In: RICKEN, Norbert; KOLLER, Christoph; KEINER, Edwin. (Eds.). Die Idee der Universität - revisited. Berlin; Heidelberg: Springer, 2014. p. 197-210.

ALHEIT, Peter; VESTER, Michael. Individualisierung oder neue Assoziation? Neue soziale Differenzierungsprozesse als praktische und theoretische Herausforderungen der Gewerkschaften. In: LEIF, Thomas; KLEIN, Ansgar; LEGRAND, Hans-Josef. (Eds.). Reform des DGB. Herausforderungen, Aufbruchpläne und Modernisierungskonzepte. Köln: Bund, 1993. p. 209-254.

AXMACHER, Dirk. Alltagswissen, Fachschulung und kultureller Imperialismus. Grenzen des Lebenswelt-Ansatzes in der Erwachsenenbildung. Grundlagen der Weiterbildung, 1 [1], p. 27-30,1990.

BECKER, Ulrich; BECKER, Horst; RUHLAND, Walter. Zwischen Angst und Aufbruch. Das Lebensgefühl der Deutschen in Ost und West nach der Wiedervereinigung. Düsseldorf; Vienna; New York; Moscow: Econ., 1992.

BOURDIEU, Pierre. Die feinen Unterschiede. Kritik der gesellschaftlichen Urteilskraft. Frankfurt am 
Main: Suhrkamp, 1987.

DAUSIEN, Bettina. Biographie und Geschlecht. Zur biographischen Konstruktion sozialer Wirklichkeit in Frauenlebensgeschichten. Bremen: Donat, 1996.

GIESECKE, Wiltrud. Habitus von Erwachsenenbildnern. Eine qualitative Studie zur beruflichen Sozialisation. Oldenburg: BIS-Verlag, 1989.

GLASER, Barney G.; STRAUSS, Anselm L. The discovery of grounded theory: strategies for qualitative research. Chicago: Aldine, 1967.

HABERMAS, Jürgen. Theorie des kommunikativen Handelns. 2 v. Frankfurt am Main: Suhrkamp, 1981.

HERMANN, Thomas. Neue Berufe im Raum der sozialen Positionen. Forschungsjournal Neue Soziale Bewegungen, H. 3, p. 33-43, 1990.

HERMANNS, Harry; TKOCZ, Christian; WINKLER, Helmut. Berufsverlauf von Ingenieuren. Biografieanalytische Auswertung narrativer Interviews. Frankfurt am Main; New York: Campus, 1984.

$K A D E$, Jochen. Erwachsenenbildung und Identität. Eine empirische Studie zur Aneignung von Bildungsangeboten. Weinheim: Deutscher Studienverlag, 1989.

KORING, Bernhard. Erwachsenenbildung und Professionstheorie. Überlegungen im Anschluß an Oevermann. In: HARNEY, Klaus et al. (Eds.). Professionalisierung der Erwachsenenbildung. Fallstudien - Materialien - Forschungsstrategien. Frankfurt am Main: Bern; New York; Paris: Peter Lang, 1987. p. 358-400.

KORING, Bernhard. Profession und Biographie. Interpretationen zur biographischen Prägung eines professionellen Habitus an der Universität. In: MAROTZKI, Winfried; KOKEMOHR, Rainer. (Eds.). Biographien in komplexen Institutionen. Studentenbiographien II. Weinheim: Deutscher Studienverlag, 1990. p. 7-44.

LEWIN, Kurt. 'Der Übergang von der aristotelischen zur galileischen Denkweise in Biologie und Psychologie. In: GRAUMANN, Carl-Friedrich. (Ed.). Kur-
t-Lewin-Werkausgabe, Bd. 1: Wissenschaftstheorie I. Berne; Stuttgart: Huber \& Klett Cotta, 1969 [1931]. p. 233-271.

MÖDING, Nori; PLATO, Alexander von. Nachkriegspublizisten: Eine erfahrungsgeschichtliche Untersuchung. In: ALHEIT, Peter; HOERNING, Erika M. (Eds.). Biographisches Wissen. Beiträge zu einer Theorie lebensgeschichtlicher Erfahrung. Frankfurt am Main; New York: Campus, 1989. p. 38-69.

NASSEHI, Armin; WEBER, Georg. Zu einer Theorie biographischer Identität. Epistemologische und systemtheoretische Argumente. Bios, 4, p. 153-187, 1990.

OEVERMANN, Ulrich. Professionalisierung der Pädagogik - Professionalisierbarkeit pädagogischen Handelns. Unpublished Lecture, FU Berlin, 1981.

PARSONS, Talcott. Societies: evolutionary and comparative perspectives. New Jersey: Prentice-Hall, 1966.

SCHEUERMANN, Antonius. Homosexualität als biographisches Konstrukt. Eine Studie über Sexualitätsbiographien. Diss. phil. Bremen: Universität Bremen, 1994.

SCHLÜTER, Anne. (Ed.). Bildungsmobilität. Studien zur Individualisierung von Arbeitertöchtern in der Moderne. Weinheim: Deutscher Studienverlag, 1993.

STRAUSS, Anselm L. Grundlagen qualitativer Sozialforschung. Datenanalyse und Theoriebildung in der empirischen soziologischen Forschung. München: Fink, 1991.

VESTER, Michael et al. Neue soziale Milieus und pluralisierte Klassengesellschaft. Endbericht des Forschungsprojekts Wandel der Sozialstruktur und die Entstehung neuer gesellschaftlich-politischer Milieus. Hannover: Universität Hannover, 1992.

VESTER, Michael et al. Soziale Milieus im gesellschaftlichen Strukturwandel. Zwischen Integration und Ausgrenzung. Frankfurt am Main: Suhrkamp, 2001.

Recebido em: 20.03.2016

Aprovado em: 30.05 .2016 
Peter Alheit é Doutor em Filosofia da Religião - Professor da Universidade de Marburg, estudioso em Teologia, Filosofia, Sociologia e Educação em Bielefeld, Goettingen, Munique, Marburg, Toronto e Kassel. Pesquisador do Instituto Comenius, Muenster, Alemanha. Atualmente, Professor Emérito da Universidade Georg-August de Göttingen, Alemanha e Diretor do Instituto Biografiae Vida, na mesma universidade, com excelente avaliação da investigação através do Conselho Científico Alemão, na área de Sociologia Cultural e Educacional. Professor visitante na Universidade Federal de Santa Maria - RS/UFSM (Brasil), na Universidade de Viena (Áustria), Universidade de Xiamen (China), e na Universidade de Chulalongkorn (Tailândia). E-mail: palheit@gwdg.de

Wilhelmsplatz 1, 37073 Göttingen, Alemanha 